\title{
Topographical Analyses of Unmanned Aerial Vehicle-Based Very High-Resolution Digital Surface Models for Archaeological Sites
}

\author{
Tekin SUSAM
}

\begin{abstract}
Unmanned aerial vehicles (UAVs) can provide very useful image data sets for exploring structures at archaeological sites. The digital surface model (DSM) is a type of data set that can be derived from UAV images by using photogrammetric materials and methods. The aim of this research is firstly to obtain a very high-resolution DSM and secondly, to perform geographic information system (GIS)-based topographical analyses of the archaeological site at Sebastopolis. The ancient city of Sebastopolis is in the Sulusaray district of the Tokat province in Turkey's Black Sea region; the site belongs to the Hellenistic/Roman period. This study shows that the multirotor type of UAV is particularly useful for applications that require flying at very low altitude above archaeological sites and that DSMs that can be derived in this way are very effective for analysing the topographical structure of archaeological sites in detail.
\end{abstract}

Keywords: GIS; very high-resolution DSM; UAV

\section{INTRODUCTION}

Documenting and analysing archaeological sites and their environments is extremely important $[1,2]$. By using aerial or non-aerial perspectives, many methods can be implemented in archaeological studies. Satellite- and other aerial-based digital elevation data sets offer archaeologists very valuable information platforms for analysis of archaeological areas [3-6]. These data sets give researchers opportunities to model terrain surfaces with greater accuracy than well-known surveying methods. DSMs are frequently based on LiDAR data or photogrammetry using aerial stereo photos. Data acquisition can, however, be costly, especially when repeated flight campaigns are required. There are studies using different methods in archaeological sites [7-10].

In recent years, improvements in the energy efficiency of batteries, the development of global navigation satellite systems (GNSSs), the impact of digital photography and related advances in the field of photogrammetry offer increasingly reliable and professional solutions for forming and producing flying platforms easily and cheaply. By integrating data with differential GPS-surveyed ground control points (GCPs), it is possible to generate digital elevation models (DEMs) with a ground resolution of under $5 \mathrm{~cm}$ and orthomosaics with resolutions of around 2 $\mathrm{cm}[11]$.

Thus, for archaeological purposes, it has become possible to build small and medium-sized aircraft that can provide coverage at a large scale. These types of UAVs are capable of longer flight times, whether at high altitude or low altitude, and greater equipment payloads. However, it is dangerous to operate them on slow, low-level flights over populated areas. That is why UAV pilots should be experts in operating them. The lower the altitude of the flight, the smaller the ground resolution; thus, it becomes possible to obtain DSM and orthophoto with more accuracy.

Good interpretation of archaeological sites relies on understanding the sites' characteristics. In this manner, UAV-based highly accurate 3D-point data sets make it possible to create new, valuable data sets showing slope, aspect, volume, cross section profiles and stream networks in the area of interest.

The slope represents the rate of change of elevation for each DEM cell. Alexakis et al. used a slope data set in order to create a risk assessment model for the archaeological sites of the Paphos area of Cyprus [12].

The aspect identifies the downslope direction of the maximum rate of change in value from each cell to its neighbours. In their study, De Reu et al. [13] used aspect data to class land forms in their archaeological study area. Grounds with southern orientation generally create a shelter of bioclimatic factors, protecting from northern winds and ensuring maximum conditions of sunshine and temperature.

The volume represents the region between the surface and the space above or below the polygon features, based on the selection made in the reference plane parameter. Cross section profiles show the change in elevation of a surface along a line.

When modelling the flow of water, one may want to know where the water came from and where it is going. Stream networks answer these questions. The aerial imagery and DEM can also be used together to create 3D perspective views of the site. The imagery is draped over the DEM by the software and can be viewed from varying elevations and aspects as dictated by the operator.

This study presents experiences with a multirotor UAV and shows the first results on digital surface modelling and the visualisation of geomorphologic features of an archaeological site. Although this study and the TEKNOMER model UAV system is specialised for this study area, it is thought that materials and methods used herein are applicable for similar archaeological sites.

\section{CASE STUDY AREA}

The ancient city of Sebastopolis in the Sulusaray district is located 69 kilometres from the city centre of the Tokat province. There are numerous architectural features, such as baths, temples, fortifications, bridges and churches, in different locations of the study area. These antique pieces indicate that the city was a dense settlement during its periods of occupation [14]. During the time of the 
Roman emperor Trajan (98-117 AD), the city was separated from the Pontus Galaticus Polaminiacus district and was included in the Cappadocia region [15]. It is situated near a major road and is close to thermal springs. It is believed to have been one of the top five cities in the Black Sea region 2000 years ago. Over time, after major wars and natural disasters, Sebastopolis was forgotten. For a few decades, the ruins have undergone renewed excavations. The study area of $1 \mathrm{~km}^{2}$ is roughly occupied and framed by the buildings and parcels (Fig. 1).

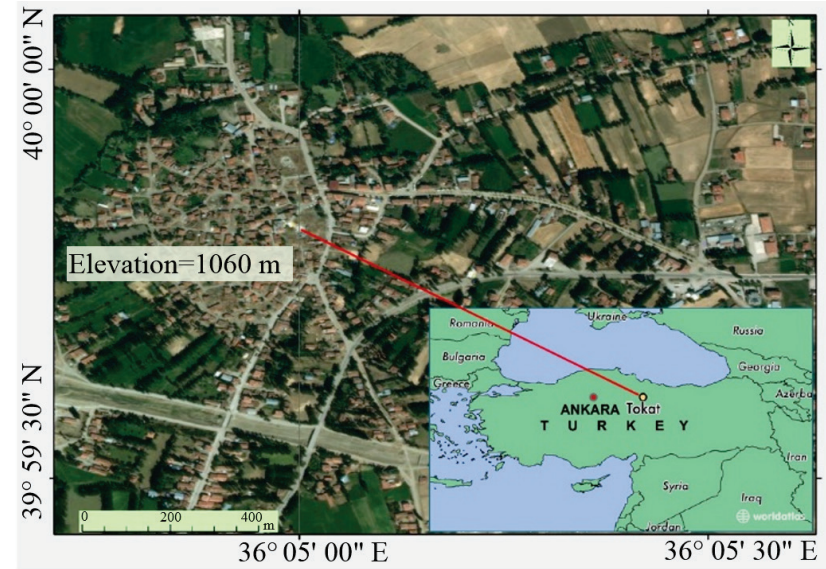

Figure 1 The study area in Turkey (bottom right), the ancient city of Sebastopolis in the Sulusaray district of Tokat, is shown on an image from Google Earth. The red line delineates the 'Roman bath' archaeological study area.

\section{AVAILABLE TOPOGRAPHIC DATA}

The first period of excavation was started on August 2013 in the Sebastopolis by Gaziosmanpaşa University. At the end of this excavation, the site was monitored by a fixed-wing UAV during one of the aerial surveys by the Department of Geomatics of Gaziosmanpaşa University. Many photographs were captured from a flight altitude of $120 \mathrm{~m}$. The resulting data sets (point cloud, orthophoto and DSM) were of insufficient quality to be used for detailed analysis. Fixed-wing platforms are capable of considerably longer flight times $(>1 \mathrm{~h})$, but multi rotors are easier to fly, can land in a smaller location, can better navigate variable terrain features and are generally more stable in variable winds [16].

\section{UAV SURVEY}

The quad-multirotor UAV was custom-designed by TEKNOMER Company and equipped with a Sony NEX-7 camera for this project (Fig. 2) [17]. The UAV is capable of operating at elevations between 0 and $2000 \mathrm{~m}$ mean sea level. In this study, the average flight altitude was between $10 \mathrm{~m}$ and $20 \mathrm{~m}$ above the terrain. The ground sample distance (GSD) was $0.42 \mathrm{~cm} /$ pixel.

The total weight, excluding cameras, is $\sim 5 \mathrm{~kg}$. The maximum flight time is around $15-20 \mathrm{~min}$ on a single 12000 mAh4S lithium polymer battery. A 3DR Pixhawk flight controller manages manual or autonomous navigation. UAV sacrifices vertical take-off and landing and generates higher quality images, due to greater platform stability.
Communication with the UAV is maintained with a $2.4 \mathrm{GHz}$ radio controller and a $\sim 433 \mathrm{MHz}$ telemetry link between the autopilot and ground station.

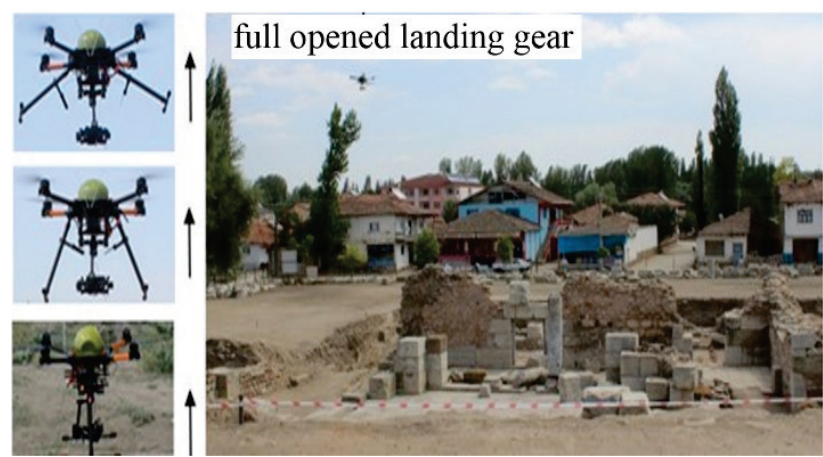

Figure 2 TEKNOMER brand quadcopter UAV - the opening of the take-off and landing gear in order to prevent occluding the photographs to be taken (centre); study area (right).

It can be flown either manually or autonomously with the aid of an integrated GNSS navigation system. It is possible for the aircraft to be operated at low levels with a very high degree of reliability and stability by an expert pilot. During the flight, the camera, with a rolling shutter, was set to take one image every $2 \mathrm{~s}$, resulting in a dataset of more than 54224 -megapixel $(6000 \times 4000)$ images.

\section{IMAGE OVERLAPS AND GROUND CONTROL POINTS}

In this study, none of the standard overlap ratios were used to minimise the occlusion areas. Both oblique and vertical photographs were taken in the study area. Out of 542 images, 542 could be calibrated (100\%).

A total of nine GCPs were used for the block adjustment. Absolute accuracy was tested against 74 checkpoints (CPs) that were established in the study area. Targets were painted to the ground using white and black colour (Fig. 3). The selection of GCPs and CPs was semirandom, making sure to include high and low points of representative structures in the study area. Before flying, a GNSS survey was conducted in order to determine GCPs and CPs. Nine GCPs were observed over two hours by the static GNSS method, using four Trimble R10 GNSS instruments. It allows obtaining valid horizontal coordinates with accuracy lower than $8 \mathrm{~mm}+1 \mathrm{ppm}$ RMS[18]. For determining the coordinates of CPs, one of the GCPs was selected as a base station. CPs were observed by a $5 \mathrm{~s}$ real-time kinematic (RTK) GNSS method from the base station. Observations were processed by using Leica Geo Office (LGO 2.0) [19].

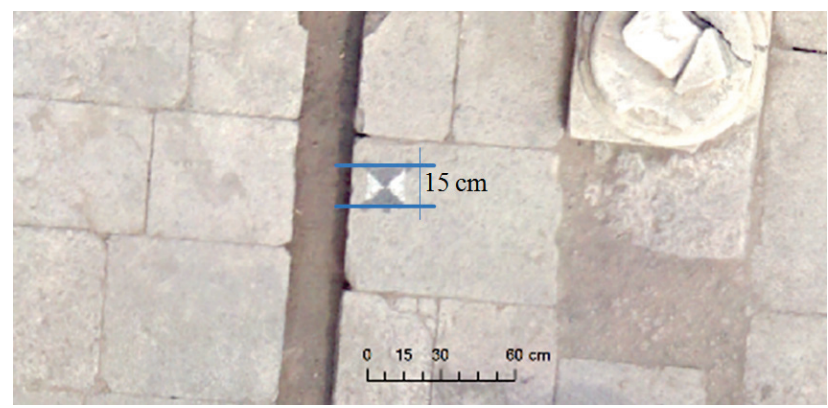

Figure $3 \mathrm{~A}$ sample screenshot of a GCP painted on marble. 
The vertical position of the GCPs and CPs were observed by geometric levelling, based on the The Turkish National Vertical Network.

\section{MODELING AND ANALYSES}

The images captured from the multirotor were processed through the semi-automatic photogrammetry package Pix4Dmapper Professional Edition, version 3.1. [20]. DSM and orthomosaic resolution were $1 \times \operatorname{GSD}(0,425$ $\mathrm{cm} /$ pixel). Point cloud density is depicted by the mean number of points in a $1 \mathrm{~m}$ cube (points $/ \mathrm{m}^{3}$ ) in the project area. The data sets were processed by using an ASUS workstation with an IntelCore64-bit CPU and an NVIDIA GeForce GTX970 graphics card, running Windows 7 Professional. ArcMAP 10.2 GIS software was used for topographical analyses [21].

At the end of processing, one very dense point cloud, one DSM and one orthophoto of the study area have been obtained. In Fig. 4, a very dense 3D point cloud model has been given.

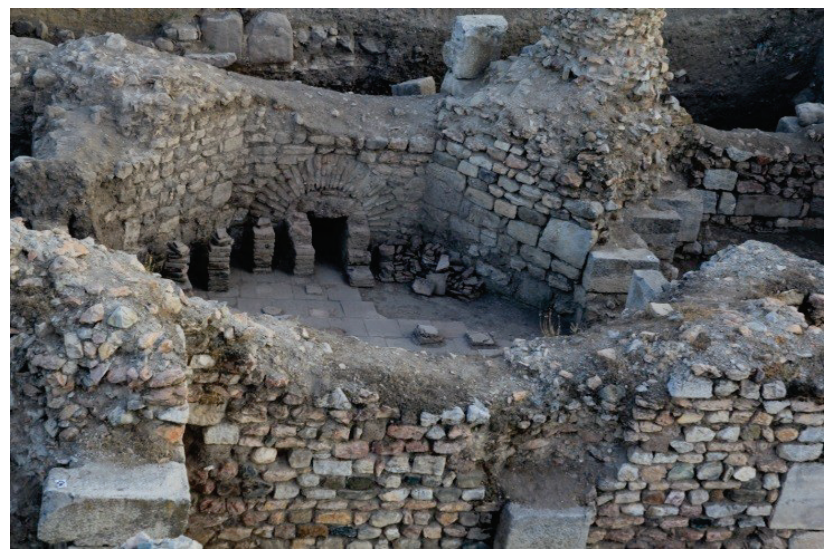

Figure $4 \mathrm{~A}$ sample perspective view of model of ruins in Sebastopolis. This is not a picture; it is a very dense 3D point cloud (63363 points $\left./ \mathrm{m}^{3}\right)$.

\subsection{DSMs and Orthophotos}

A digital elevation model (DEM) is a bare-earth raster grid referenced to the Turkish National Vertical Control Network. Another type of DEM is the DSM, which captures the natural and built features on the Earth's surface. Because of the oblique viewing angles, it has become possible to eliminate occlusions, which is difficult to accomplish with LiDAR

The very high-resolution DSMs allow us to gain more information about the terrain that was examined. The areas coloured with dirty white show higher elevations, and the light blue ones show lower elevations. It can be seen from the DSM that the elevation varies between $1060 \mathrm{~m}$ and $1066 \mathrm{~m}$ from the mean sea level (Fig. 5). In this study, elevation, hill shade, slope, aspect in raster format, section profiles and stream networks in vector format were derived from DSM data by using GIS-based tools in order to visualise the height differences in detail.

An orthophoto map is a combination of vertical and oblique aerial photographs. It is of great benefit because it is cheaper to produce and update than conventional maps. It is on a larger scale, allowing for more detail, and shows more detail than topographic maps. It is possible to identify the small features on the orthophoto map. An orthophoto created in this study is given as a raster image in Fig. 6.

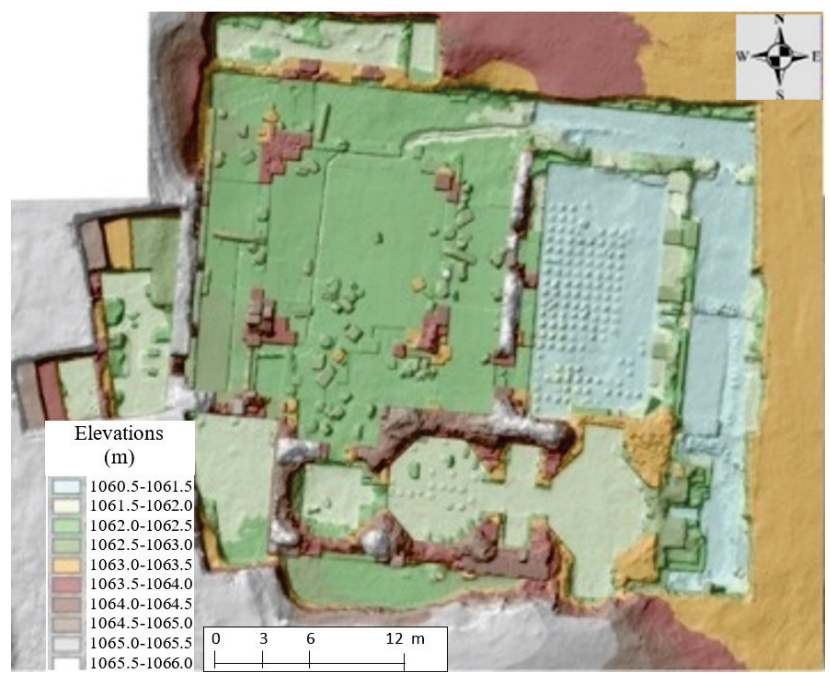

Figure 5 Shaded DSM representation of the study area.

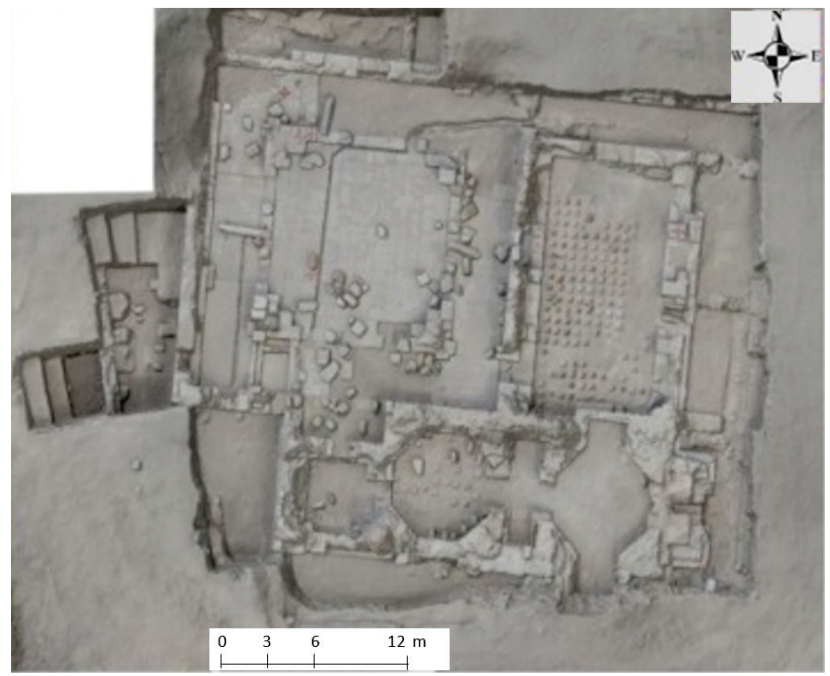

Figure 6 Shaded orthophoto representation of the study area.

\subsection{Topographic Analyses \\ 6.2.1 Hillshade}

Hillshade is an alternative method to the use of isolines for representing surfaces. The model provides subtle shadings, which we naturally perceive as depth, helping to make the image look three-dimensional (Fig. 7).
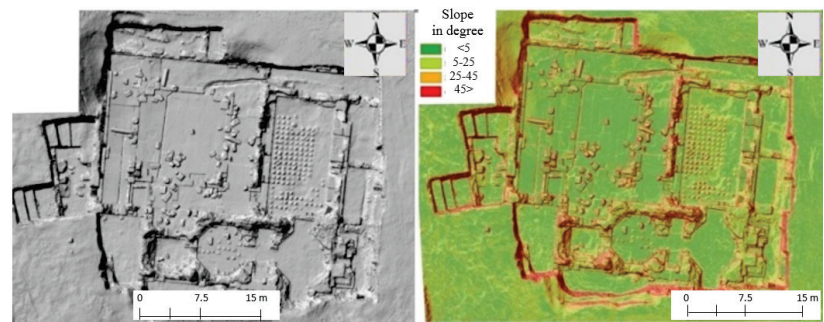

Figure 7 An example of a hillshade created from DSM raster data (left). The location of the sun (i.e. the azimuth or angle of illumination) has been set to the northwest corner. The hillshaded slope which is derived from the DSM of the study area is at right.

As can be seen at the left in Fig. 7, the hillshade representation is an effective method for visualising terrain elevations in two dimensions. It is possible to use this data 
set as a baseline map in order to enhance other data sets, including aspect and slope data sets, DSMs, orthophotos and point clouds.

\subsubsection{Slope}

Another useful detail about the terrain is how steep it is. Its grade is used, among other things, to estimate erosion potential. Statistical analysis of the image at right in Fig. 7 shows that the slope inclination of the surface varies between $0^{\circ}$ and $89.88^{\circ}$. The mean value is $14.80^{\circ}$. The slope of the ground surface affects the amount of erosion that may occur. Duley and Hays [22] conclude that runoff increases rapidly from a $0 \%$ slope to a $3 \%$ slope but increases only slightly for each additional percent. They combined slope information with the wave erosion model to create the overall erosion potential map in archaeological study areas.

\subsubsection{Aspect}

Each cell denotes the direction of its faces in aspect maps. An aspect layer (Fig. 8) was derived from the DSM in order to identify the slope direction of hill faces. The cardinal directions of north, south, east and west were coded in degrees from $1^{\circ}$ to $360^{\circ}$.

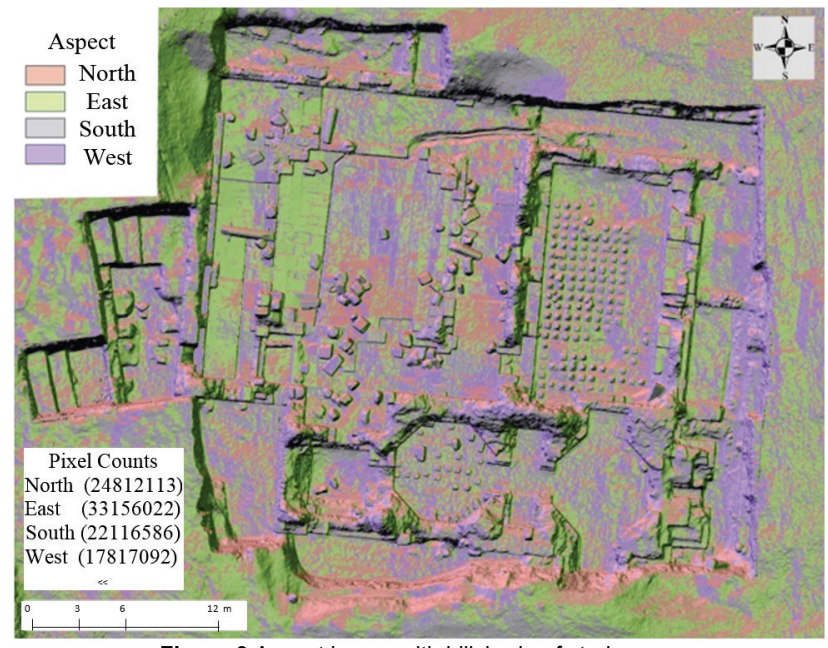

Figure 8 Aspect image with hillshade of study area.

In this case, it could be observed that the east-facing and north-facing slopes are predominant (Fig. 8), in comparison with the west-and north-facing slopes. Aspect information is an important factor in analysing the degradation of archaeological sites. The wave erosion model is based upon wind direction and aspect.

In an archaeological study performed by David Ebert \& Matthew Singer [23] in the boreal forest ecozone of west-central Manitoba (Canada), aspect values were used in erosion modelling.

\subsubsection{Contours}

Lines that connect points of equal height $(Z)$ are called contours. For a better view and in order to show the very high resolution capacity of the DSM, contours were generated at intervals of $2,5 \mathrm{~cm}, 5 \mathrm{~cm}$ and $25 \mathrm{~cm}$ (Fig. 9).

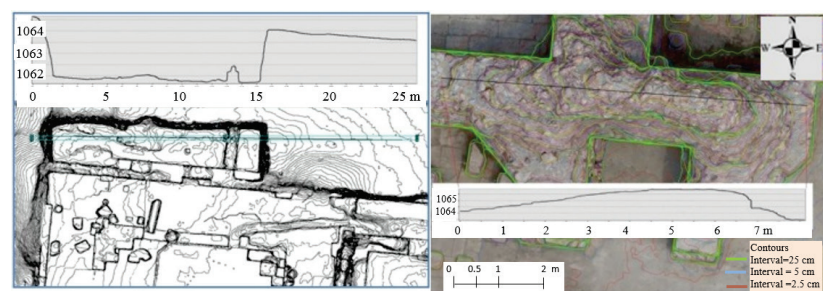

Figure 9 Two contour plots of the study area; the left panel is a plot of the contour lines at $5 \mathrm{~cm}$ intervals. The right panel is the contour line values coded by colour at $2,5 \mathrm{~cm}$ intervals.

Cross-sections on panels are necessary for measurement of earthwork volumes or views of the ground perpendicular to the base line; they indicate ground elevations at points of change in the ground slope.

\subsubsection{Volume with UAV Data}

Volume measurement based on multirotor UAV data is an extremely fast, accurate and cost-effective method to analyse volumes in archaeological sites. To calculate volume, a 'base' surface is defined by the perimeter of the measurement area. Volume measurements can be repeated to see how the volume has changed over time.

In order to obtain the values of the excavated soil volume, Pix4D software was used by following the required steps [24].

The software computes the volume automatically with the parameters given. It computes the volume $(V)$ with Eq. (1):

$$
V=L_{i} \times W_{i} \times H_{i}
$$

where $L_{i}=$ the length of the cell, $W_{i}=$ the width of the cell and $H_{i}=$ the height of the cell. The length and width are equal to the project's GSD.

$H_{i}$ is given by Eq. (2):

$$
H_{i}=Z_{\mathrm{T}}-Z_{\mathrm{B}}
$$

where $Z_{\mathrm{T}}=$ the terrain altitude of each cell and $Z_{\mathrm{B}}=$ the base altitude of each cell.

Therefore, the volume of any cell is given by Eq. (3):

$$
V=G S D^{2} \times\left(Z_{\mathrm{T}}-Z_{\mathrm{B}}\right)
$$

The volume error for each cell is given by Eq. (4):

$E_{i}=L_{i} \times W_{i} \times Z_{e i}=1,5 \times G S D^{3}$

where: $E_{i}=$ the volume error of one cell, $Z_{e i}=$ the error in $Z$ direction of the cell.

The total cut volume error ( $\left.T C V_{\mathrm{E}}\right)$ is given by Eq. (5):

$T C V_{\mathrm{E}}=E_{\mathrm{C} 1}+E_{\mathrm{C} 2}+\ldots+E_{\mathrm{C} N}$

where $E_{\mathrm{C} 1, \ldots, N}=$ cut volume error for cells1 through $N$. If the cell has fill volume, then the cut volume error $E_{\mathrm{C}}$ is 0 . The total fill volume error $\left(T F V_{\mathrm{E}}\right)$ is given by Eq. (6):

$T F V_{\mathrm{E}}=E_{\mathrm{F} 1}+E_{\mathrm{F} 2}+\ldots+E_{\mathrm{F} N}$ 
where $E_{\mathrm{F} 1, \ldots, N}=$ fill volume error for cell $i, \ldots, N$. If the cell has cut volume, then the fill volume error $E_{\mathrm{F}}$ is 0 .

Total volume error $\left(T V_{\mathrm{E}}\right)$ is given by Eq. (7):

$T V_{\mathrm{E}}=T C V_{\mathrm{E}}+T F V_{\mathrm{E}}$

Total amount of soil that had been excavated by the end of 2014 was calculated as $3390.70 \pm 9.25 \mathrm{~m}^{3}$ at the study area (Fig. 10 left). The amount of soil that was excavated in 2014 was calculated as $991.05 \pm 2.74 \mathrm{~m}^{3}$ (Fig. 10 right). The study by Arango, C. \& Morales, A [25] shows that the volume calculated by using UAV-based DSM data is more accurate than the volume obtained with point-based total station data. In this present study, the results were not compared with different measuring methods.
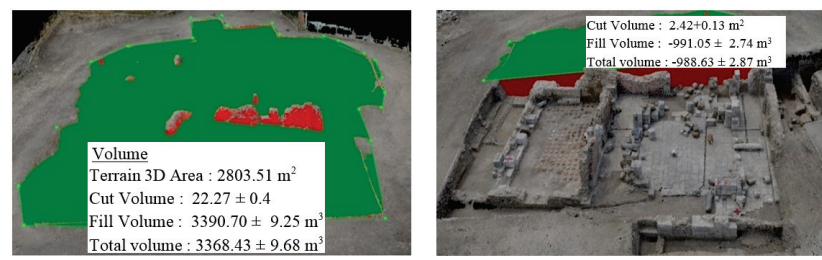

Figure 10 Volume calculations, two 3D models showing the base planes and fill volume of the whole study area (left) and the amount of soil that was excavated in 2014 (right).

\subsubsection{Cross-Sectional Profiles}

Cross-sectional profiles were extracted from UAVbased very high-resolution DSM. It is possible to extract channels, walls, stones and their heights from the profiles that have been given oin Fig. 11. It is noticeable that the small variations in elevation of terrain are shown in detail.

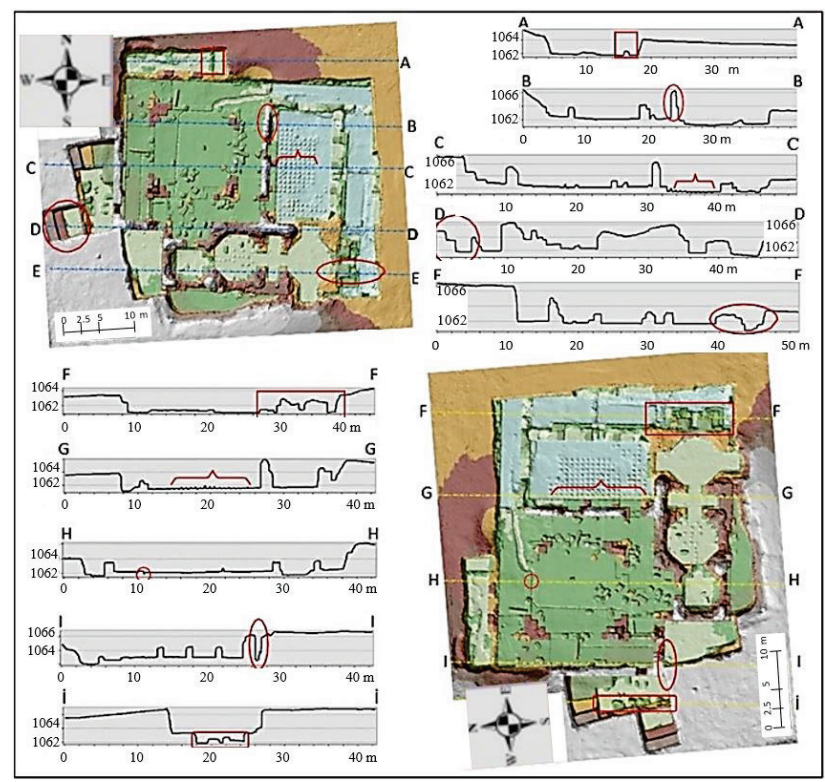

Figure 11 Longitudinal topographic profile on the W-E and N-S axis. Units are in meters, both elevation and distance.

\subsubsection{Stream Order}

Streams are water flow paths. They are derived from DSMs, and their details are based on DSM resolution. If DSM resolution is high, it is possible to discern small streams, but that is not possible if the resolution is low.
That is why higher resolution and accuracy of DSM data are required for hydrological delineation in flatter terrains. In this study, a stream network is modelled by using the appropriate ArcGIS tools, following Strahler's stream ordering method [26] (Fig.12).

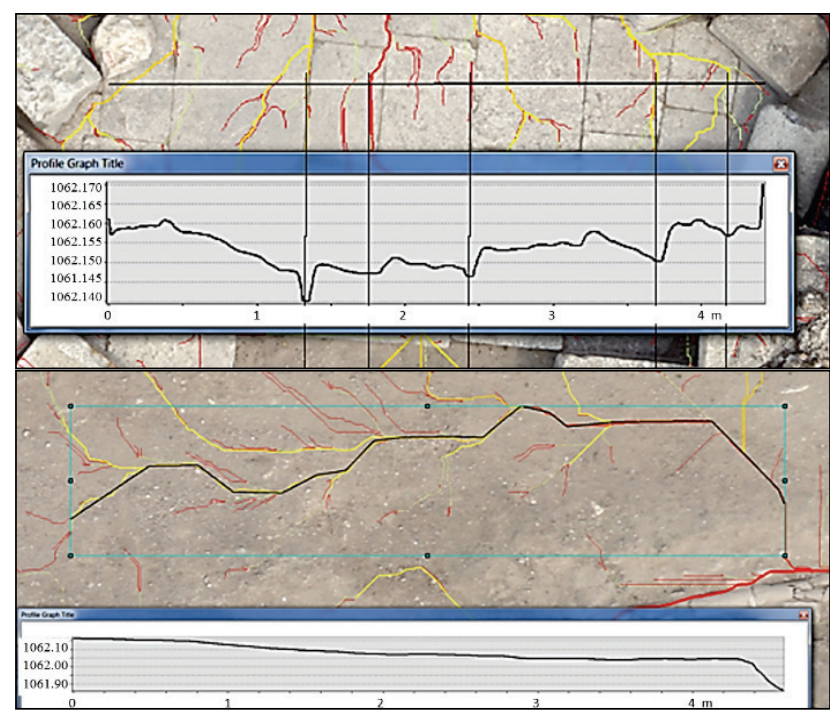

Figure 12 Small stream flow paths (top), the profile graph of a small stream flow path (bottom). It is obvious that the elevation difference between first point and end is quite small and slope is quite low.

\section{ACCURACY ASSESSMENT}

The root mean square error (RMSE) is a frequently used measure of the difference between values computed by a model and the values actually measured from the environment that is being modelled. It is defined as the square root of the mean squared error:

$R M S E=\sqrt{\frac{\sum_{i=1}^{n}\left(X_{\mathrm{m}, i}-X_{\mathrm{c}, i}\right)^{2}}{n}}$

where $X_{\mathrm{m}}$ is measured values, $X_{\mathrm{c}}$ is computed values at point $i$ and $n$ is the number of sample points.

The photogrammetric software provides differences between the observed coordinates and the modelled coordinates of GCPs and CPs. Despite the slightly irregular flight pattern and flight altitude, the UAV succeeded in obtaining a highly detailed and accurate 3D model of the terrain. The mean RMSE of the models were reported by software as $\pm 2.2 \mathrm{~cm}$ between the computed and measured coordinates of the 9 GCPs. The individual RMSEs for the $x$-, $y$ - and $z$-axes are $\pm 2.9, \pm 3.2$ and $\pm 2.9 \mathrm{~cm}$ respectively. The surveyed elevations at the $74 \mathrm{CP}$ locations were compared against the elevations extracted from the DEM surface to provide a more precise estimate of the absolute elevation error for the DSM surface. The mean RMSE reported for CPs by the software of Pix4D mapper is $\pm 0.037 \mathrm{~m}$.

\section{CONCLUSION}

As a result, there is no doubt that very low altitude UAV-based 3D recording fills a methodological gap within the archaeological mapping process. With this new technology, archaeologists involved in projects around the 
world can thus explore the archaeological data in 3D perspective on screen.

Depending on the materials and methods used for topographical analyses of archaeological sites, the quality and detail of excavation documentation, 3D visualisation, volume calculation, slope, aspect and other sources of data will differ. As to the complexity of the study area analysed, there are many different structures, such as regular, eroded and destroyed surfaces, vertical and horizontal holes, gates, walls, small and big stones, vertical and horizontal marble columns, waste water channels and water pipes.

This kind of complexity in an archaeological site requires a combination of different materials, methods, softwares and new technological systems. That is why, in this study, many cutting-edge systems such as UAV, GNSS, remote sensing, GIS and very close photogrammetry were used in order to process, analyse and visualise. There is now a huge DSM for detailed knowledge about the newly excavated archaeological site.

Very low altitude digital photogrammetry using a UAV can work reasonably well with complex, clean structures such as excavated sites, since its main result is a surface model rather than an elevation model. In excavated archaeological sites, the data capture method and procedure allows quick capture of very large sets of point data. This made it possible to draw every single block of visible structures in the study area.

Since the study area was cleaned from vegetation before flying, the UAV-based very low altitude aerial measurements on the site became very effective and accurate to a level never before attained. The very dense point cloud data set (63 363 points $/ \mathrm{m}^{3}$ ) extracted from very high-resolution images gives a better $3 \mathrm{D}$ representation than traditional methods. It provides an excellent record of an archaeological landscape or site, enabling preservation and future monitoring. The results summarised in this study show clearly the benefit of the higher resolution, lowflying altitude, vertical and oblique images and higher overlap (both forward and at the sides). This type of surveying offers the opportunity to fill a gap in the effective range and detail for archaeological sites.

Thus, this study explicitly represents the strengths of UAVs, which can support archaeological research significantly. In addition to UAVs, the GIS-based approach is one of the most promising tasks in interdisciplinary archaeological research.

These technologies would allow archaeologists to focus their work on specific areas at archaeological site. Any archaeologist could potentially benefit from this type of model produced by UAVs. By using these systems together, archaeologists can gain detailed knowledge and make better choices about how to protect or restore archaeological sites.

\section{Acknowledgements}

Tokat Provincial Directorate of Culture and Tourism are thanked for their financial support to the project of archaeological excavations at Sebastopolis. The author appreciates the anonymous referees of Archaeological Prospection for their helpful and useful comments and suggestions on an earlier version of this paper. The author also thanks Alper Ak for his valuable contribution.

\section{REFERENCES}

[1] De Reu, J., Bourgeois, J., Bats, M., Zwertvaegher, A., Gelorini, V., De Smedt, P., Chu,. W., Antrop, M., De Maeyer, P., Finke, P., Van Meirvenne, M., Verniers, J., \& Crombé, P. (2013). Application of the topographic position index to heterogeneous landscapes. Geomorphology, 186(15), 39-49. https://doi.org/10.1016/j.geomorph.2012.12.015

[2] Parcak, S. H. (2009). Satellite Remote Sensing for Archaeology. New York, NY, Routledge. https://doi.org/10.4324/9780203881460

[3] Lasaponara, R. \& Masini, N. (Eds.). (2012). Satellite Remote Sensing: A New Tool for Archaeology. Dordrecht: The Netherlands, Springer. https://doi.org/10.1007/978-90-481-8801-7

[4] Dorel, M., Marcel, T., \& Liviu, M. (2009). The morphotopographic and cartographic analysis of the archaeological site Cornesti 'Iarcuri', Timis County, Romania, using computer sciences methods (GIS and remote sensing techniques). Ann. Univ. Tibiscus Comp. Sci. Series, $\operatorname{VII}(2009)$, 249-262

[5] Turrero, P., Domínguez-Cuesta M. J., Jiménez-Sánchez, M., \& García-Vázquez, E. (2013). The spatial distribution of Palaeolithic human settlements and its influence on palaeoecological studies: a case from northern Iberia. Journal of Archaeological Science, 40(12), 4127-4138. https://doi.org/10.1016/j.jas.2013.06.003

[6] Hritz, C. (2014). Contributions of GIS and satellite-based remote sensing to landscape archaeology in the Middle East. Journal of Archaeological Research, 22(3), 229-276. https://doi.org/10.1007/s10814-013-9072-2

[7] Verhoeven, G.J.J., (2009). Providing an archaeological bird's-eye view: an overall picture of ground-based means to execute low-altitude aerial photography in archaeology. Archaeological Prospection, 16, 233-249. https://doi.org/10.1002/arp.354

[8] Chiabrando, F., Nex, F., Piatti, D., \& Rinaudo, F. (2011). UAV and RPV systems for photogrammetric surveys in archaeological sites: two tests in the Piedmont region (Italy). Journal of Archaeological Science, 38(3), 697-710. https://doi.org/10.1016/j.jas.2010.10.022

[9] Haubeck, K \& Prinz, Torsten. (2013). A UAV-Based LowCost Stereo Camera System for Archaeological SurveysExperiences from Doliche (Turkey). ISPRS - International Archives of the Photogrammetry, Remote Sensing and Spatial Information Sciences, XL-1/W2, 195-200. https://doi.org/10.5194/isprsarchives-XL-1-W2-195-2013

[10] Ghitley, T. G. (2015). Unmanned aerial vehicles (UAVs) for documenting and interpreting historical archaeological sites: part II - return of the drones. Technical Briefs in Historical Archaeology, 9, 41-48.

[11] Hugenholtz, C. H., Whitehead, K., Brown, O. W., Barchyn, T. E., Moorman, B. J., LeClair, A., Riddell, K., \& Hamilton, T. (2013). Geomorphological mapping with a small unmanned aircraft system (sUAS): feature detection and accuracy assessment of a photogrammetrically-derived digital terrain model. Geomorphology, 194, 16-24, https://doi.org/10.1016/j.geomorph.2013.03.023

[12] Alexakis, D., Agapiou, A., Themistocleous, K., Lysandrou, V., Sarris, A., \& Hadjimitsis, D. (2013). Natural and human hazard assessment of the archaeological sites of Paphos area (Cyprus) with the use of remote sensing and GIS. Bulletin of the Geological Society of Greece, 47(3), 1448-1457. https://doi.org/10.12681/bgsg.10983

[13] Malaperdas, G. \& Zacharias, N. (2018). A geospatial analysis of Mycenaean habitation sites using a geocumulative versus habitation approach. Journal of Geoscience and Environment Protection, (6), 111-131. https://doi.org/10.4236/gep.2018.61008 
[14] Alkan, A. (2004). Sebastopolis antik kenti (TokatSulusaray). Retrieved from Ankara University Open Archive System, http://acikarsiv.ankara.edu.tr/browse/3284/. https://doi.org/10.1501/ankara-3284

[15] http://www.kultur.gov.tr/EN,114000/the-tokat---historicalruins.html

[16] Oliver, W. \& Bryan, M. (2017). Monitoring tropical debriscovered glacier dynamics from high-resolution unmanned aerial vehicle photogrammetry, Cordillera Blanca, Peru. The Cryosphere, 11, 2463-2480. https://doi.org/ 10.5194/tc-11-2463-2017

[17] http://akteknomer.com

[18] www.graftek.com.tr/urunler/trimble-r10-gnss-alicisi/115/1/

[19] http://www.sistemas.com.tr/yazilimdetay?ktg=totalstation\&alt=yazilim\&k=3\&urn=leica-geo-office \&syf $=1$

[20] https://pix4d.com, access time 08/11/2017

[21] https://esri.com, access time 08/11/2017

[22] Duley, F. L. \& Hays, O. E. (1932). The effect of the degree of slope on runoff and soil erosion. Journal of Agricultural Research, 45, 349-360.

[23] David E. \& Matthew S. (2004). Modelling erosion and archaeological potential using GIS. Research School of Archaeology and Archaeological Sciences, University of Sheffield, December 2004, issue 8. ISSN 1365-3881

[24] https://support.pix4d.com/hc/en-us/articles/202559239-

[25] Arango C., \& Morales, A. (2015). Comparison between multicopter UAV and total station for estimating stockpile volumes. The International Archives of the Photogrammetry, Remote Sensing and Spatial Information Sciences, Vol. XL1/W4, 131-135, Toronto, Canada. https://doi.org/10.5194/isprsarchives-XL-1-W4-131-2015

[26] Strahler, A. N. (1952). Hypsometric (area-altitude) analysis of erosional topography. Geological Society of America Bulletin, 63(11), p. 1117. https://doi.org/10.1130/00167606(1952)63[1117:HAAOET]2.0.CO;2

\section{Contact information:}

Tekin SUSAM, Assoc. Prof. Dr.

Gaziosmanpaşa University,

Taşlıçiftlik Campus, 60250 Tokat, Turkey

E-mail: tekin.susam@gop.edu.tr 